\title{
A polifonia discursiva da Copa de 1994: os discursos autorizados sobre o tetracampeonato
}

\section{Fausto Amaro e Ronaldo Helal}

\section{Resumo}

0 artigo discute a produção acadêmica e jornalística em torno da Copa do Mundo de Futebol de

1994. Tomando como base a noção de discursos autorizados, desenvolvida por Guedes (2010/2011) inspirada em Bourdieu (1983), estudamos 0 discurso construído em torno desse evento a partir de oito enciclopédias e livros de Copas, do Jornal do Brasil (JB) e de edições comemorativas das revistas Época e Placar. A produção acadêmica investigada foi oriunda de anais de evento, artigos em periódicos e capítulos de livro. Observamos que enquanto o discurso autorizado da imprensa esportiva carece de reflexão e se deixa levar pelo senso comum, ao discurso acadêmico falta simplesmente variedade de repertório temático, referencial teórico e ampliação no número de autores. Os trabalhos acadêmicos abordaram, principalmente, a hermenêutica da derrota, a questão da identidade nacional, a publicidade e a presença do rádio.

\section{Palavras-Chave}

Esporte. Mídia. Discurso. Jornalismo. Copa do Mundo.

Fausto Amaro I austoarp@hotmail.com Doutorando em Comunicação pela Universidade do Estado do Rio de Janeiro (UERJ).

Ronaldo Helal | rhelal@globo.comDoutor em Ciências da Doutor em Sociologia pela New York University. Professor do Programa de Pós-graduação em Comunicação da Universidade do Estado do Rio de Janeiro (UERJ).

\section{Introdução}

Nosso foco neste artigo está na junção dos campos de jogo e do acadêmico, destacando os principais pontos de discussão levantados sobre a Copa do Mundo de 1994. 0 discurso da imprensa provém de oito enciclopédias e livros de Copas (vide referências bibliográficas), das edições do Jornal do Brasil (de 17/06/94 a 20/07/94) e de números comemorativos das revistas Época e Placar. Simoni Guedes (2010/2011) situa o jornalismo e a academia como produtores do que ela denomina de "discursos autorizados" sobre o futebol. Em Bourdieu (1983), entendemos essa autorização social da fala de outrem como uma das atribuições que deveriam ser incorporadas por uma ciência que se proponha a estudar o discurso. Ele afirma que: "Não falamos a qualquer um; qualquer um não 'toma a palavra' [...] A ciência do discurso deve levar em conta as condições de instauração da comunicação, porque as condições de recepção esperadas fazem parte das condições de produção" (1983, p. 161).

Nesse jogo de poder discursivo, temos na figura do receptor das falas autorizadas da imprensa tanto 0 
torcedor regular do futebol (que conhece as regras, é apaixonado por seu clube, acompanha os jogos) quanto o "torcedor de Copa", cuja paixão por futebol reaparece a cada quatro anos e se confunde com 0 seu amor pela nação. A mídia deve assim produzir uma fala que atenda a ambos os grupos. São essas condições específicas de produção da narrativa que devemos ter em mente quando analisamos um discurso, seja jornalístico ou acadêmico.

Essas narrativas, oriundas de variados atores, pautam a mídia quadrienalmente e forjam uma história própria do futebol, cujo acionamento de memória é efetivado nos períodos rituais de Copa do Mundo (GUEDES, 2002).

\section{0 discurso da imprensa sobre a Copa}

0 baixo nível técnico dessa Copa foi mencionado em três das enciclopédias consultadas: ${ }^{1}$ Todas as Copas, editada pelo Jornal Lance (s/a), O Jogo Bruto das Copas (1997) e $O$ mundo das Copas (2010). As demais obras jornalísticas optaram por ressaltar que essa Copa havia sido superior tecnicamente a de 1990.0 protagonismo coube a Romário, vice-artilheiro e eleito pela FIFA o craque da competição. Apelidado de "baixinho", devido à sua estatura, foi alçado ao posto de herói da Copa.

\section{0 técnico Carlos Alberto Parreira e seu} coordenador técnico, Mário Jorge Lobo Zagallo, recebiam inúmeras críticas da imprensa pelo desempenho abaixo do esperado nas Eliminatórias e pelo estilo defensivo que os dois imprimiram à Seleção. Diante da Bolívia, em La Paz, o Brasil sofreu sua primeira derrota na história dessa fase da competição, que qualifica para a Copa. As derrotas, segundo a imprensa, adviriam desse não-jogar o "verdadeiro futebol brasileiro" ofensivo, baseado no toque de bola e na habilidade individual. 0 jornalista Teixeira Heizer (1997, p. 297, grifos nossos) define dessa forma a equipe brasileira da época e seu técnico:

Parreira havia descido aos rés do chão com aquele grupo de jogadores medíocres, mas valentes que, paradoxalmente, chegou ao título, enquanto as poderosas seleções de 1950 e 1982, praticantes de um estilo inigualável, não o fizeram, numa relação de inexplicabilidade do futebol.

Nessas eliminatórias, a classificação só veio no último jogo, com uma vitória sobre o Uruguai, no Maracanã. A vitória foi creditada em grande medida à atuação destacada de Romário, autor dos dois gols, convocado especialmente para aquele jogo, já que antes estava sendo preterido devido a desentendimentos com a comissão técnica. A falta de confiança na equipe brasileira por parte da imprensa brasileira se contrapunha ao favoritismo com que éramos vistos internacionalmente. 0 Brasil era apontado como favorito pelos técnicos entrevistados pela La Gazzeta dello Sport - "0 
Brasil recebeu 188 votos contra 155 dados à Alemanha e 152 à Itália" (JB, 17/06/1994, p. 5).

Anteriormente aos primeiros jogos da Copa, as matérias aguardavam a recuperação de Romário, que sentia os efeitos de uma antiga lesão. Quando de sua volta aos treinos, 0 titulo da matéria é "Alegria no Treino" ( $J B$, 19/06/1994, p. 10) - bastante evocativo da representação que era desenvolvida em torno do jogador. Igualmente enfocada é a aplicação tática e técnica dos brasileiros, seja na forma do esforço nos treinos e jogadas ensaiadas, seja na repetição de movimentos, vide 0 título da seguinte matéria: "Se falta talento, sobra aplicação" (JB, 19/06/1994, p. 11).

As controvérsias e as diferentes lentes com que se enxergam um mesmo fato marcam muitas vezes o discurso jornalístico sobre essa Copa. Ao comentar a recusa de Romário em sentar ao lado de Muller e Bebeto no voo para os Estados Unidos, Veja e Placar adotaram formas bem distintas de narrar o mesmo episódio. Enquanto a primeira focou no caráter do jogador, a segunda optou por fugir dessa polêmica e recontar o fato de maneira mais leve e cômica. Vejamos:

Encrenqueiro como sempre, [Romário] anunciou que não se sentaria entre Bebeto e Muller no avião fretado pela CBF, como estabelecera a comissão técnica (Veja, 1994a, p. 18, grifos nossos).

0 lugar de Romário no avião estava marcado entre Bebeto e Muller e ele fazia questão da janela. "0 avião tem mais de cem janelas, Ro- mário. Você só não pode viajar na poltrona do comandante porque daí 0 avião cai”, 0 artilheiro ouviu de um de seus mais bem-humorados companheiros (Placar, 1994, p. 10).

0 discurso autorizado dos jornalistas também permite que esses profissionais fujam de um tom mais formal em sua escrita e adotem muitas vezes o linguajar popular e, consequentemente, incorporem as vestes do torcedor. Heizer (1998, p. 450), por exemplo, em seu livro, que poderíamos esperar objetivo pelo teor "enciclopedístico", tem um arroubo apaixonado de torcedor ao exclamar: "Parabéns, Brasil, Tetracampeão!". Essa liberdade na linguagem é um dos muitos elementos distintivos entre 0 discurso do jornalismo esportivo e 0 acadêmico.

Regressando à Copa, no primeiro jogo, vitória brasileira. Dois a zero sobre a Rússia e um gol de Romário. A Enciclopédia do Lance descreve assim o jogo: "0 pragmático futebol de resultados do técnico Parreira dava seu primeiro passo com sucesso nos campos da América do Norte" (s/a, p. 166). Após esse primeiro jogo, o título da matéria do $J B$ dizia de forma otimista: "Seleção brasileira estréia como campeã" (21/06/1994, p. 3), destacando o fato de Brasil ter ganhado, ao contrário de outras seleções tidas como favoritas.

No segundo jogo, nova vitória, dessa vez sobre os camaroneses por três a zero. Mais uma vez 0 destaque ficou para a atuação do time, e não para a goleada: "Novamente 0 que se viu durante quase todo o primeiro tempo foi um futebol chato, muito 
eficiente na marcação, mas com pouca criatividade" (Lance!, s/a, p. 167). 0 interessante nesse excerto é 0 adjetivo utilizado para descrever a qualidade do jogo: chato. Quais seriam os critérios para essa definição? Ora, foi um jogo de três gols marcados, o que comumente chamaríamos de goleada. Além disso, com um jogador de Camarões expulso, 0 campo ficou mais aberto para as jogadas. Fica a dúvida: o que seria não-chato nesse caso? A manchete do $J B$, por seu turno, no mesmo tom da matéria sobre o primeiro jogo, destaca: "0 melhor da Copa" (25/06/1994, p. 1). Armando Nogueira comentava com certo desalento:

0 Brasil não joga o futebol do meu encantamento. Dificilmente jogará. A concepção tática de Parreira só funciona quando a equipe contra-ataca. $E$ ́ opção dele. Está dando bons frutos. É o futebol de resultados. Entre a minha exigência um tanto romântica e o realismo incontornável de Parreira, sei que 0 Brasil inteiro, sedento de glória fica com Parreira. Sejamos todos felizes, eternamente $(J B$, 25/06/1994, p. 8, grifos nossos).

No terceiro jogo, foram registradas vaias - "Vaias para a seleção" (JB, 29/06/1994, p. 6). Empate com os suecos, que o Brasil voltaria a enfrentar nas semifinais. Romário foi quem igualou o placar para o Brasil. Assim define o Lance! a primeira fase do Brasil na Copa: "A equipe, embora, primeira colocada do grupo, não se livrou das pressões e das críticas feitas pelo futebol feio" (s/a, p. 168). Nesse jogo, a manchete do caderno de esportes do $J B$ foi mais dura, contrapondo-se às suas manchetes nos jogos anteriores: "Brasil cai na real. Empate com a Suécia revela as deficiências de um time preso às limitações do meio-campo" (29/06/1994, p. 1). Sérgio Noronha afirma peremptoriamente que "não fomos, nesta Copa, o Brasil brasileiro" ( $J B, 30 / 06$, p. 7). Mais uma vez percebemos o discurso jornalístico recaindo em essencializações simplificadoras. Afinal, quem é capaz de definir com total acuidade o que seria esse "Brasil brasileiro"?

Classificado em primeiro, com o melhor aproveitamento do Mundial, o Brasil enfrentou os anfitriões norte-americanos nas oitavas-definal do torneio. A capa do caderno de Esportes do $J B$ foi: "Eu te amo! Romário ouviu de Bebeto o sentimento de todo brasileiro, mas criticou futebol 'pobre' do time" (05/07/1994, p. 1). 0 potencial "sobrenatural" dessa dupla faz-se presente também no livro de Geraldo Muzzi: "o Brasil venceu os Estados Unidos por 1x0. Bebeto marcou 0 único gol do após receber um passe mágico de Romário" (2010, p. 138).

Três a dois. Foi com esse placar apertado que o Brasil passou pela Holanda e avançou às semifinais contra a Suécia. Com gols de Romário, Bebeto e Branco, nessa ordem, o Brasil voltava a uma semifinal depois de 16 anos. Nesse jogo, a carência de habilidade no meio-campo brasileiro foi mais uma vez alvo de críticas: "Com Mauro Silva, Dunga e Mazinho, o meio-campo brasileiro marcava muito; com Zinho, criava nada" (RIBAS, 2010, p. 351). Paulo Vinícius Coelho, ao comentar a igualdade sem gols ao fim do primeiro tempo, afirma: "Um 0 X 0 insosso, que reforçava a ideia que brasileiros e holandeses tinham de suas 
próprias equipes. 0 Brasil pensava de si próprio um time aquém da tradição" (2010, p. 127).

$0 J B$ destacou a presença de Branco no jogo, extremamente criticado pelos jornalistas: "[...] sua imagem ao deixar o campo, ofegante, como os torcedores, feliz, como qualquer brasileiro, e malandro como todo o time, foi a mais completa tradução da seleção de ontem" (10/07/1994, p. 1, grifos nossos). Nesse trecho, nos deparamos com uma construção narrativa que enfatiza sobremaneira a malandragem, ao mesmo tempo em que minimiza 0 esforço dos jogadores, ao igualá-lo ao dos torcedores.

A semifinal foi vencida por um a zero com um gol de oportunismo de Romário: "A Suécia, até então, tinha permitido poucas cabeçadas dos adversários contra seu arco e não tomara nenhum gol de cabeça. A disciplina tática dos jogadores suecos foi vencida e o Rose Bowl foi tomado por um grande grito de 'Olée” (Lance!, s/a, p. 172). Percebe-se aqui o contraponto entre a "picardia" presente no grito e a "rigidez disciplinar" sueca. É sobre essa dicotomia que se assenta muitas vezes o discurso da imprensa esportiva brasileira nessa e em outras Copas. $0 J B$ prefere acionar a memória dos torcedores para a reedição da final contra Itália na Copa do México. 0 título da manchete do Caderno de Esportes do dia 14 de julho era: "Como em 70" e 0 tom das reportagens era de extremo otimismo com a possibilidade de conquista do inédito tetra. A essa altura da competição, Muzzi (2010, p. 138) assevera que Romário já era alcunhado de "Salvador da Pátria" pelos torcedores brasileiros, apelido que carrega fortes tons nacionalistas e grande carga de responsabilidade. 0 atleta, por sua vez, imbuiu-se desse papel de herói e pretendia compartilhar a conquista com seus semelhantes: "Vou dedicar o tetra ao povo sofrido" (JB, 13/07/1994, p. 11). No mesmo período, quando implantava o bemsucedido plano real, o então ministro da fazenda Fernando Henrique Cardoso afirmara que "não era nenhum 'salvador da pátria"' (ROCHA, 1996, p. 13). A atitude de Romário de assumir publicamente suas qualidades destoa da falsa modéstia, comum entre os brasileiros, e presente na fala de Fernando Henrique Cardoso (FHC).

A vitória na final foi difícil e saiu apenas nos pênaltis, pela primeira vez na história das Copas. Assaf e Martins não deixam de apontar, assim como todos os outros jornalistas, o futebol pragmático e defensivista adotado por Parreira e Zagallo, mas ressaltam dois pontos importantes: nos primeiros dois anos à frente da seleção, Parreira utilizou-se de uma equipe com "futebol alegre e ofensivo" e, em defesa daquela seleção, pontuam que as críticas soam injustas, uma vez que "foi assim que derrubamos 24 anos de frustrações, conquistando um título inédito para os outros 197 membros da Fifa" (1998, p. 229). Heizer (1997, p. 303), por sua vez, concede contornos heroicos à conquista:

A nova verdade era cristalina: um time fraco, execrado pela torcida, dirigido por um técnico vilipendiado pela imprensa, armou-se para, nos limites de suas forças e de sua técnica simples, 
arrancar um resultado extraordinário, que jamais será esquecido pela torcida brasileira.

A análise das edições do Caderno de Esportes do $J B$ expôs que durante essa Copa o tema nacionalista não esteve muito presente, o que pode apontar para o início de um declínio da pátria de chuteiras, que seria esmiuçado por Helal e Soares (2003) alguns anos depois. Falamos em nacionalidade no sentido de uma associação das conquistas e fracassos na Copa a esferas que exacerbam o futebol e esbarram no sucesso ou derrocada do próprio país. Podemos supor que isso se deva a falta de "brasilidade" da equipe formada por Parreira e Zagallo, que encontraria apenas em Romário o seu legítimo representante.

Na Veja (1994b, p. 9, 13), como exceção à afirmação anterior, a conquista do mundial redime o Brasil de problemas maiores em outras esferas tidas como mais "sérias" da sociedade: "Depois de tantas desgraças - a corrupção de Collor, o governo Itamar, a morte de Ayrton Senna -, o país levanta a cabeça e comemora ter, de novo, o melhor futebol do mundo". Serve também como explicação para um país em mutação, que se apresentava de uma maneira nova aos olhares nacionais e estrangeiros: "0 futebol acaba de revelar uma imagem surpreendente do país. 0 Brasil tetracampeão do mundo é disciplinado, metódico, obediente, organizado, solidário e bem preparado - um país muito diferente daquela terra do jeitinho e da improvisação".
Além de Romário, essa também foi a Copa de Dunga. A Copa de sua readmissão no rol dos heróis nacionais. Sua imagem de "jogador esforçado" legou-lhe uma ambígua posição na lembrança jornalística: "A Era Dunga [...] inspirada na mediocridade do voluntarioso médio brasileiro" (HEIZER, 1997, p. 297). Em uma mesma frase, utilizam-se duas palavras de conotações adversas: mediocridade como valor negativo e voluntarioso como ponto a favor em seu estilo de jogo. 0 adjetivo voluntarioso é ainda desdobrado em matéria da Placar: "Falar em Dunga é falar em raça, determinação, valentia" (Placar, 1994, p. 21). Em 26 de junho, o JB estampou na capa do caderno de Esportes: "Nasce uma era". Em 16 de julho, no dia anterior à final, as palavras são as seguintes: "Quem diria que o símbolo de uma fase negativa do futebol brasileiro - a Era Dunga, nome dado ao futebol de pouca criatividade e muita limitação do time na Copa de 90 - estaria hoje entre os melhores da Copa de 94" (JB, 16/07/1994, p. 1). Os qualitativos presentes nos jogadores esforçados como Dunga são quase sempre dúbios e lamuriosos, diferentemente daqueles de nossos heróis "macunaímicos" como Romário.

De modo geral, o discurso jornalístico assemelhase muito quando trata da Copa de 1994. Há certa concordância tácita entre os jornalistas sobre essa Copa quando é lançada a questão da essência do futebol brasileiro. Fala-se em uma seleção pragmática, com poucos recursos técnicos, mas com um ataque talentoso, formado por Romário e Bebeto. 0 título do capítulo sobre essa Copa no 
livro de radialista Barbosa Filho (2004) resume bem o discurso comum na opinião pública: "Vencemos e não convencemos".

Esse consenso jornalístico na construção da memória do evento, no entanto, não deve ser confundido com narrativa uníssona. Vozes destoantes estão presentes. 0 próprio Barbosa Filho (2004, p. 226) traça um retrato otimista daquela seleção, que não vimos ser tão compartilhado pelos seus colegas de imprensa nos livros analisados:

0 time era muito bom, escalado pelo técnico Parreira. Tínhamos uma defesa sólida com Ricardo Rocha, Márcio Santos e como regra três o jogador Aldair, um meio de campo excelente com Raí, Mauro Silva, Dunga e Zinho e um ataque onde despontava a inteligência de Bebeto e 0 talento de Romário.

\section{A reflexão acadêmica: quais temas foram abordados pelos pesquisadores?}

Para empreender a revisão bibliográfica que nos propomos nesse tópico, efetuamos primeiramente uma busca em algumas plataformas de armazenamento de artigos científicos, como Scielo, Redalyc, Univerciencia e Google Acadêmico, no mês de março de 2013. Além disso, acessamos os anais dos principais congressos nas áreas de História (Anpuh), Ciências Sociais (Anpocs) ${ }^{2}$ e Comunicação (Compós e Intercom). Nessa investigação preliminar, encontramos cerca de 30 trabalhos que dialogavam em algum nível com nosso objeto: a Copa de 1994. Excluímos muitos da análise por serem "genéricos" sobre as Copas e suas representações simbólicas. 0s demais se encontram de alguma forma representados nas linhas que seguem. Priorizamos os trabalhos disponíveis em portais de divulgação acadêmica, o que evidentemente deve ter deixado de fora monografias, dissertações e teses que não tiveram seus conteúdos publicados separadamente em formato de artigos científicos.

\subsection{A narrativa heroica e vilânica}

Começamos abordando 0 artigo "A construção de narrativas de idolatria no futebol brasileiro" (2003). Nele, Helal analisa, pelo viés do mito do herói "à brasileira", as narrativas das trajetórias de Zico e Romário. Helal parte dessa dualidade biográfica para fazer comparações maiores sobre o ethos nacional. Sua hipótese é que valorizaríamos mais o sucesso sem esforço.

0 estudo do discurso, efetuado nesse artigo, nos revela como a trajetória de Romário descrita pelos jornais coincide com uma narrativa mais ou menos consolidada sobre os heróis nacionais e que parece mudar muito pouco entre um e outro grande atleta alçado a esse posto. Romário é um elemento de reforço para nossa 
suposta identidade futebolística, em um elenco reconhecido mais por sua disciplina tática e força do que por seus talentos individuais. Paradoxalmente, ele representou um momento de transição em um êxodo cada vez mais precoce dos nossos craques para o futebol europeu - parte do processo de internacionalização, profissionalização e mercantilização desse esporte em nível mundial (LOPES; FAGUER, 1999, p. 177).

Podemos enumerar alguns temas-chave levantados por Helal (2003) em seu estudo sobre 0 jogador: origem pobre, malandragem, futebol força $\mathrm{x}$ futebol arte, dicotomia ordem (Dunga) e desordem (Romário). Ainda que 0 foco de Fernando Bittencourt (2009, p. 182) em seu artigo não seja a Copa de 1994, ele também faz um adendo sobre Romário:

[...] não podemos nos furtar à conexão entre 0 sucesso da raça e a participação decisiva e/ ou heroica de Romário, que guarda, aparentemente - talvez não só no imaginário popular -, características positivadas de nossas relações sociais, a saber, moreno, malandro, esperto etc.

Em outro artigo, Helal e Soares (2003, p. 10) reverberam uma contradição exposta nos jornais entre Romário e Dunga:

Dunga era como se fosse uma antítese daquilo que os brasileiros idealizam como sendo 0 "futebol-arte". A conquista da Copa de 1994, em que 0 capitão da equipe, apesar de ter lhe proporcionado sua redenção no esporte, foi celebrada como a vitória da "malandragem", simbolizada no futebol de Romário.
Se até aqui falamos de vitórias e heróis, a pesquisadora Leda Costa traz um novo olhar para interpretarmos a Copa de 1994. Sobre o discurso da imprensa, Costa (2012, p. 1) é contundente: "Embora se proponha neutra e crítica, valores como coragem, covardia, talento e falta de talento etc., serão acionados pela imprensa esportiva de acordo com o resultado do jogo". A autora traça um breve histórico das narrativas jornalísticas sobre as derrotas mais emblemáticas da seleção, tomando 1950 como a gênese desse discurso sobre a derrota. Daí, ela propor o que denomina de "hermenêutica da derrota". Em uma nota de rodapé, ela afirma que a Copa de 1994 seguiu um caminho oposto ao que normalmente ocorreria, ou seja, foi inicialmente criticada para somente ao final ser ufanada.

Sobre Dunga e seu posto, ora de antagonista a Romário ora de protagonista da conquista, Costa (2011, p. 7) aponta que:

Poucos vilões como Dunga, em 1990, conseguiram ser considerados como a quase que total negação do futebol brasileiro. Entretanto esse mesmo Dunga, em 1994, será considerado um dos heróis do tetracampeonato mundial, jogador cujas virtudes foram evocadas em 2006 logo após a saída da seleção da Copa do Mundo daquele ano.

Costa se utiliza, assim, do discurso sobre a vilania para desenvolver uma extensa argumentação sobre nossa tendência a sempre buscar culpados pela derrota e a contrapor nosso futebol (e, metonimicamente, nossa brasilidade) ao 
europeu. Por fim, ela questiona a validade de um mote frequentemente reiterado pelos jornalistas esportivos para criticar técnicos e jogadores: eles não estariam representando a essência do futebol brasileiro ou do futebol arte. A autora mostra que, por ser socialmente construída, essa essência não pode ser naturalizada. Naturalizá-la é um equívoco que desencadeia outros mais, como a própria busca de culpados nas derrotas e a exigência de que sempre joguemos esse ideal de futebol brasileiro.

Outra autora que pesquisa as representações em torno do jogador Romário é a antropóloga Simoni Guedes (1995, p. 26, 30), optando pelo enfoque nas "dramatizações sobre a rebeldia" e tendo como corpus os jornais $O$ Globo e $J B$. Ela enfatiza a dimensão da "disciplina", presente no episódio da expulsão de Romário da equipe que disputou grande parte das Eliminatórias, opondo-a a arte inerente ao grande jogador, e ressalta a dicotomia entre 0 craque e 0 coletivo. Nesse sentido, Romário seria um herói rebelde, menos "macunaímico" que agressivo. Em resumo, conforme Guedes (1995, p. 31, grifos da autora), "[...] é a relação entre esta exclusão por indisciplina e seu retorno tão bem sucedido que redimensiona sua imagem, alçando-0, através do transe da Copa de 94, ao panteão mais nobre do futebol brasileiro".

Em outro artigo, Guedes (2010/2011) considera Romário exemplar do que qualifica como discursos rebeldes do futebol. 0 atacante artilheiro teria subvertido a lógica que coloca o jogador submisso a apenas jogar, e não falar. Guedes (2010/2011, p.
9) utiliza este caso como emblema de algo maior:

"Romário, na Copa do Mundo de 1994, não apenas jogou, mas falou o tempo todo e falou sobre o povo, identificando-se como alguém do povo [...] com esta reivindicação diz que o povo não precisa de portavoz". Outro artigo da mesma autora (2009), com motivação parecida, contrapõe essa voz "popular" legitimada de Romário àquela de João Lyra Filho, acadêmico e dirigente esportivo na Copa de 1954. Ao contrário do primeiro, Lyra Filho adotava um discurso racialista e elitista que atribuía ao próprio povo a culpa das mazelas sociais.

\subsection{Futebol e Identidade Nacional}

Retornando à Helal, em texto escrito com Cesar Gordon, eles tratam da suposta crise no futebol brasileiro, do ponto de vista técnico e estrutural, nas últimas décadas do século XX. Segundo os autores, a conquista de 1994 não foi suficiente para retirar a palavra crise da "pauta na imprensa esportiva" (2002, p. 49). Essa crise estaria manifesta principalmente no discurso da imprensa, que não enxergaria mais "o futebol como metonímia da nação" (HELAL, 2012, p. 37). Para sustentar seu argumento, Helal (2010, p. 37) afirma que: "A derrota na final para 0 Uruguai em 1950 e a conquista do tricampeonato em 1970 foram sentidas como derrota e vitória, respectivamente, de projetos de nação brasileira. Já as vitórias de 1994 e 2002 não transcenderam 0 terreno esportivo". Para Gastaldo (2003, p. 7), esse esmaecimento da relação Seleção-nação verificado principalmente em 1998, poderia estar ligado ao 
título conquistado em 1994: "A vitória na Copa de 1994, após um longo período de 24 anos sem um título em Copas do Mundo, promoveu uma rearticulação de significados nesta relação entre a avaliação da seleção brasileira e a avaliação do povo brasileiro".

Em trabalho sobre a narrativa midiática das alteridades e rivalidades entre Brasil e Argentina tendo como palco o universo esportivo, Helal (2006, p. 5) destaca o início de uma resposta da imprensa argentina às provocações dos jornais brasileiros para com Maradona em 1994, ao mesmo tempo em que mantinham a usual admiração pelo estilo de jogo brasileiro. 0s periódicos argentinos, assim como os brasileiros, ressaltavam a importância de Romário, alcunhado de "El Chapulín" pelos jornalistas portenhos, a despeito do esquema de Parreira. Pensamos que esse tipo de análise, de natureza comparativa, é extremamente oportuno, principalmente em um mundo globalizado como o nosso em que muito se escreve sobre identidades homogeneizadas e nacionalidades arrefecidas.

Na esteira de Roberto DaMatta e Gilberto Freyre, Everardo Rocha $(1995,1996)$ retoma, em dois artigos complementares, a interpretação do Brasil por meio de suas dualidades dicotômicas, tais como: "Indivíduo/pessoa, malandro/Caxias, carnaval/semana da pátria, jeitinho/regra ou casa/rua" (1995, p. 48, grifos do autor). A despeito disso, o que me interessou nesse artigo foi a explicação, na forma de indagações, que
Rocha busca para o fato de preferirmos as Copas de 58, 62 e 70, e até as de 50 e 82, em que fomos derrotados, do que a do tetracampeonato, em 1994.

As representações tradicionais sobre 0 Brasil e sua Seleção não se aplicariam a essa Copa, onde 0 pragmatismo e a dedicação estiveram mais presentes que a picardia e o talento nato de nossos jogadores. A organização sobrepujava um estilo de jogo tido como mais livre e menos metódico. Acerca disso, Rocha (1996, p. 11, grifos do autor) ressalta que tanto a imprensa especializada quanto o público em geral teriam preferido "ganhar a copa de outra maneira ou, mais radicalmente, que ganhar com um futebol feio, esquemático, fechado, sem arte, baile ou categoria não valia à pena ou ainda que não havia sido uma vitória do verdadeiro futebol brasileiro". Em outro momento, ele se pergunta à semelhança de Costa (já citada no presente artigo): "E o que é isto o que chamamos de verdadeiro futebol brasileiro ou, antes, podemos dizer, as verdades do Brasil através do futebol?" (1995, p. 56, grifos do autor).

\subsection{Rádio, publicidade e novos rumos de pesquisa}

Em "1994: a última Copa do Mundo narrada pelo 'garotinho' Osmar Santos”, Patrícia Rangel (2012) investiga a cobertura radiofônica desta Copa, destacando como principais fatos o uso inédito de aparelhos celulares na cobertura e a aposentadoria forçada por motivos médicos do narrador que dá título a seu artigo. Esse avanço representava, além de um ganho tecnológico, uma 
melhora na qualidade do áudio que era recebido pelos ouvintes. Rangel nos revela que foi graças a esse novo aparato técnico que a Rádio Globo pôde dar 0 furo de reportagem ao vivo sobre a fuga de Romário da concentração. Ademais, no mesmo artigo, ela reafirma os mitos da imprensa de que: "0 Brasil, liderado pelos atacantes Romário e Bebeto e dirigido pela dupla Parreira-Zagallo, jogava um futebol pragmático" (RANGEL, 2012, p. 196).

Mais uma abordagem possível, e bem distinta das que vimos até aqui, é 0 artigo de Carmen Rial (2005) sobre a publicidade na TV e em revistas durante a Copa do Mundo de $1994 .{ }^{3}$ Rial destaca que em períodos de Copa a publicidade enfoca temas ligados à identidade nacional e ao patriotismo, concedendo maior espaço aos negros e mulatos, tidos como legítimos representantes de nosso estilo de jogo. Em seguida, a autora analisa os comerciais da Rider e das cervejas Antarctica e Brahma. Nesse período, a propaganda ainda estaria impregnada por uma série de estereótipos na representação dos negros, associados a aspectos da natureza (o que poderia ser sintetizado pela equação: branco $=$ intelecto; negro $=$ corpo).

Uma fonte de análises ainda não explorada, pelo que averiguamos, é o filme oficial daquela Copa:
Two Billion Hearts ou, em português, Todos

os Corações do Mundo. Dirigido pelo brasileiro Murillo Salles, o filme foi lançado em 1995. São aproximadamente 105 minutos de documentário, mesclando o desconhecimento inicial dos norteamericanos com a festa que ocorria dentro dos estádios e as especificidades da torcida de cada país. As nacionalidades e seus estereótipos se manifestam nas arquibancadas. As palavras do narrador renderiam um estudo à parte sobre seu discurso, que reforça as imagens clássicas do futebol, ligando-o à arte e à natureza - é claro que, sendo um filme oficial da Copa, era esperado que o folclore do esporte ocupasse papel de destaque. Fala-se, por exemplo, de um Maradona associado à leveza do vento e a sua "magia do pé esquerdo" e de uma Alemanha "sempre metódica".

Outrossim, por que não mais pesquisas que enfoquem a cobertura radiofônica? ${ }^{4} \mathrm{Ou}$ ainda, como teria sido a cobertura pela televisão? Afinal, nessa Copa, a audiência acumulada desse veículo chegou a 33 bilhões de pessoas (Veja, 1994b, p.

35); pela primeira vez um grande canal americano (a rede $\mathrm{ABC}$ ) transmitiu os jogos ao vivo; e a Rede Globo contou com quatro câmeras exclusivas (Veja, 1994a, p. 56-57). Salvo erro na pesquisa bibliográfica, não há nenhum artigo que enfoque

Na verdade, o período de análise excedeu esse intervalo. 0 período de coleta compreendeu as seguintes datas: março a setembro de 1994; maio a julho de 1995; maio a agosto de 1998; primeiro semestre de 2000.

Ainda que tenhamos percebido um aumento nas produções acadêmicas sobre o tema, inclusive à nível de graduação, com maior interesse dos alunos pela pesquisa empírica nas gravações radiofônicas e entrevistas com radialistas. Nesse sentido, a monografia Rádio e Copa do Mundo através das décadas: análise da cobertura da rádio Guaíba dos Mundiais de 1982 e 2010 (2011), de Rodrigo Martins de Oliveira, defendida na Faculdade de Biblioteconomia e Comunicação da UFRGS, serve de exemplo para 0 que dizemos. 
esse meio. Aos impressos e seu discurso recaem a maior parte das atenções. É claro que devemos levar em conta as dificuldades de pesquisa que envolvem os meios audiovisuais, ainda mais na era pré-internet, quando o conteúdo era mais restrito ao público em geral.

Algumas questões ainda são passíveis de ser trabalhadas. Será que a imprensa estrangeira elogiava tanto o selecionado nacional como diziam os jornais brasileiros? Afinal, qual era a imagem de nossa seleção aos olhos estrangeiros? Quais eram os atributos associados a Romário e Dunga? As mesmas questões acionadas na análise de periódicos nacionais podem vir à tona em estudos comparativos com periódicos estrangeiros.

\section{Pontos finais}

Alguns pontos devem, nesse momento, ser rememorados. Vimos ao longo desse artigo como a narrativa sobre a Copa de 1994 rendeu muitas publicações jornalísticas, na forma de livros e enciclopédias. Algo normal e esperado, pois Copas do Mundo atraem a curiosidade do leitor atemporalmente e, por isso, vendem. Por outro lado, a academia carece de maior variação nos objetos abordados dentro da grande temática fornecida por essa Copa. Além disso, encontramos uma concentração de autores da região Sudeste e, mesmo assim, em pequeno número, o que representa um viés específico de corpus de análise e talvez de corpo teórico. Parece-nos assim que enquanto o discurso autorizado da imprensa esportiva carece de reflexão e se deixa levar pelo senso comum, ao discurso acadêmico falta simplesmente variedade de repertório temático e ampliação no número de autores.

A imprensa esportiva foi impiedosa durante (vide a narrativa do $J B$ e das revistas investigadas) e após (vide os livros e enciclopédias) a Copa. $\mathrm{Na}$ letra impressa, aquela seleção era a pior representação possível do estilo de jogar brasileiro, à exceção de um ou outro jogador, mas mesmo assim conseguiu conquistar o título. Essa conquista demandou uma mudança no discurso e uma valorização do esforço e do jogo coletivo daquele grupo. Não obstante, coube a Romário uma considerável parcela do crédito da opinião pública. Ele era o bastião de brasilidade responsável pelo triunfo. Dito isto, entendemos o porquê de uma concentração de produções acadêmicas sobre a representação criada em torno de Romário. Ele foi deveras a grande figura midiática dessa Copa. Ademais, abordouse a hermenêutica da derrota, a questão da identidade nacional, a publicidade e a presença do rádio. A Copa de 1994 não é, assim, uma fonte já esgotada de pesquisa. Há muito a ser feito, ainda que um bom percurso já tenha sido trilhado pelos autores vistos aqui.

\section{Referências}

ASSAF, Roberto; MARTINS, Clóvis. Mundo das Copas do Mundo. Rio de Janeiro: Irradiação Cultural, 1998. BARBOSA FILHO. Brasil em Copas do Mundo. São Paulo: Editora Panorama, 2004. 
BITENCOURT, Fernando. Espaço sobre algumas implicações do futebol e da Copa do Mundo para o Brasil: identidade e ritos de autoridade. Revista Brasileira de Ciências do Esporte, v. 30, n. 3, p. 173189, maio 2009.

BOURDIEU, Pierre. A economia das trocas linguísticas. In: ORTIZ, Renato (Org.). Bourdieu: sociologia. São Paulo: Ática, 1983. p. 156-183.

COELHO, Paulo Vinícius. 0s 55 maiores jogos das Copas do Mundo. São Paulo: Panda Books, 2010.

COSTA, Leda. Alteridades imaginadas. As narrativas da derrota e os vilões da seleção brasileira em Copas do Mundo. Mídia e identidade nacional. In: REUNIÃO ANUAL DA ASSOCIAÇÃO NACIONAL DE PÓS-GRADUAÇÃO E PESQUISA EM CIÊNCIAS SOCIAIS, 35., 2011, Caxambu. Anais... Caxambu: ANP0CS, 2011.

Hermenêutica da derrota. Imprensa esportiva e seleção brasileira nas Copas do Mundo. In: REUNIÃO ANUAL DA ASSOCIAÇÃO NACIONAL DE PÓSGRADUAÇÃO E PESQUISA EM CIÊNCIAS SOCIAIS, 36., 2012, Águas de Lindóia. Anais... Águas de Lindóia: ANPOCS, 2012.

DUARTE, Orlando. Enciclopédia: todas as Copas do Mundo. São Paulo: MAKRON Books, 1998.

GASTALD0, Édison. A Pátria na Imprensa de Chuteiras: futebol, mídia e identidades brasileiras. In: REUNIÃO ANUAL DA ASSOCIAÇÃO NACIONAL DE PÓS-GRADUAÇÃO E PESQUISA EM CIÊNCIAS SOCIAIS, 27., 2003, Caxambu. Anais...Caxambu: ANPOCS, 2003.

GUEDES, Simoni Lahud. 0 Brasil nas Copas do Mundo: tempo suspenso e história. In: Reunião Brasileira de Antropologia, 23. Gramado, 2002. Anais... Gramado: ABA, 2002.

- Discursos autorizados e discursos rebeldes no futebol brasileiro. Esporte e Sociedade, v. 6, n. 16, $2010 / 2011$.
0 salvador da pátria. Considerações em torno da imagem do jogador Romário na Copa do Mundo de 1994. Pesquisa de Campo, n. 1, p. 23-41, 1995.

Guia da Copa, Veja, São Paulo. Ano 27, edição 1344, 1994a. Edição Especial.

HELAL, Ronaldo. A construção de narrativas de idolatria no futebol brasileiro. Revista Alceu, v. 4, n. 7, p. 19-36, jul./dez. 2003.

Eles e nós: imprensa e rivalidade futebolística entre Argentina e Brasil. In: REUNIÃO ANUAL DA ASSOCIAÇÃO NACIONAL DE PÓS-GRADUAÇÃO E PESQUISA EM CIÊNCIAS SOCIAIS, 30., 2006, Caxambu. Anais... Caxambu: ANPOCS, 2006. As novas fronteiras do "País do Futebol".

Pesquisa Rio/Faperj, v. 11, p. 37-40, 2010. ; GORDON JUNIOR, C. A crise do futebol brasileiro: perspectivas para o século XXI. Eco-Pós, Rio de Janeiro, v. 5, n. 1, p. 37-55, 2002.

; SOARES, Antonio Jorge Gonçalves. 0 declínio da pátria de chuteiras: futebol e identidade nacional na Copa do Mundo de 2002. In: REUNIÃO ANUAL DA ASSOCIAÇÃO NACIONAL DE PROGRAMAS DE PÓSGRADUAÇÃO EM COMUNICAÇÃO (Intercom), 12., 2003 Recife. Anais... Recife: UFPE, 2003.

HEIZER, Teixeira. 0 jogo bruto das Copas do Mundo. Rio de Janeiro: Mauad, 1997.

LOPES, José Sérgio Leite; FAGUER, Jean-Pierre. Considerações em torno das transformações do profissionalismo no futebol a partir da observação da Copa de 1998. Estudos Históricos, v. 13, p. 175-191, 1999.

MUZZI, Geraldo. Brasil em todas as 19 Copas do Mundo: 1930 - 2010. São Paulo: Pontes Editores, 2010.

Placar, São Paulo, n. 8, jul. 1994. Edição Especial.

RANGEL, Patrícia. 1994: a última Copa do Mundo narrada pelo "garotinho" Osmar Santos. In: RANGEL, Patrícia; GUERRA, Márcio. (Org.). 0 rádio 
e as Copas do Mundo. Juiz de Fora: Juizforana

Gráfica e Editora, 2012. p. 195-206.

RIAL, Carmen. Japonês está para TV assim como mulato para cerveja: imagens da publicidade. In: REUNIÃO ANUAL DA ASSOCIAÇÃO NACIONAL DE PÓS-GRADUAÇÃO E PESQUISA EM CIÊNCIAS SOCIAIS, 19., 1995, Caxambu. Anais... Caxambu: ANPOCS, 1995.

RIBAS, Lycio Vellozo. 0 mundo das Copas. São Paulo: Lua de Papel, 2010.

ROCHA, Everardo. As invenções do cotidiano: 0 descobrimento do Brasil e a conquista do Tetra (parte 1). Pesquisa de Campo, v. 2, p. 41-58, 1995.

As invenções do cotidiano: 0 descobrimento do Brasil e a conquista do tetra (parte 2). Pesquisa de Campo, Rio de Janeiro, v. 3/4, p. 11-20, 1996.

É tetra. Veja, São Paulo, ano 27, n. 29-A, edição 1349A, 1994b. Edição Especial.

TODAS as copas. Rio de Janeiro: Lance!, s/a. 


\section{The discursive polyphony on the 1994 World Cup: authorized discourses on the tetra championship}

\section{Abstract}

This article discusses the academic and journalistic production about the 1994 Soccer World Cup. Basing on the notion of authorized speeches, developed by Guedes (2010/2011) and inspired by Bourdieu (1983), we study the discourse constructed about this event on eight encyclopedias and books about World Cups, Jornal do Brasil (JB) newspaper and the special commemorative editions of Época and Placar magazines. The academic production analyzed was collected from the annals of conferences, articles published on academic journals and chapters of books. We observed that the authorized discourse lacks reflection and is led by common sense while the academic discourse lacks variety of themes, theoretical references and authors. The academic works dealt mainly on the hermeneutics of defeat, the question of national identity, the advertising and the presence of radio.

\section{Keywords}

Sport. Media. Discourse. Journalism. World Cup.

\section{La polifonía discursiva del Mundial de Fútbol de 1994: discursos permitidos en el tetracampeonato}

\section{Resumen}

El artículo discute la producción académica y periodística acerca de la Copa de Mundo de Fútbol de 1994. Basándose en la noción de discursos autorizados, desarrollada por Guedes (2010/2011), inspirada en Bourdieu (1983), investigamos el discurso construido acerca de este evento desde ocho enciclopedias y libros de Mundiales, del diario Jornal do Brasil y de ediciones conmemorativas de las revistas Época y Placar. La producción académica investigada se originó de anales de evento, artículos en periódicos y capítulos de libros. Observamos que el discurso autorizado de la prensa deportiva necesita de reflexión y se deja llevar por el sentido común, mientras que al discurso académico le falta simplemente una variedad de repertorio temático y una ampliación de autores. Los trabajos académicos abarcaron, principalmente, la hermenéutica de la derrota, la cuestión de la identidad nacional, la publicidad y la presencia de la radio.

\section{Palabras-Clave}

Deportes. Medios de comunicación. Discurso. Periodismo. Copas del Mundo. 


\section{Expediente}

A revista E-Compós é a publicação científica em formato eletrônico da Associação Nacional dos Programas de Pós-Graduação em Comunicação (Compós). Lançada em 2004, tem como principal finalidade difundir a produção acadêmica de pesquisadores da área de Comunicação, inseridos em instituições do Brasil e do exterior.

\section{E-COMPÓS I www.e-compos.org.br I E-ISSN 1808-2599}

Revista da Associação Nacional dos Programas

de Pós-Graduação em Comunicacão.

Brasília, v.16, n.3, set./dez. 2013

A identificação das edições, a partir de 2008

passa a ser volume anual com três números.

\section{CONSELHO EDITORIAL}

Afonso Albuquerque, Universidade Federal Fluminense, Brasil Alberto Carlos Augusto Klein, Universidade Estadual de Londrina, Brasil Alex Fernando Teixeira Primo, Universidade Federal do Rio Grande do Sul, Brasil Ana Carolina Damboriarena Escosteguy, Pontifícia Universidade Católica do Rio Grande do Sul, Brasi

Ana Gruszynski, Universidade Federal do Rio Grande do Sul, Brasil Ana Silvia Lopes Davi Médola, Universidade Estadual Paulista, Brasil André Luiz Martins Lemos, Universidade Federal da Bahia, Brasil Ângela Freire Prysthon, Universidade Federal de Pernambuco, Brasil Antônio Fausto Neto, Universidade do Vale do Rio dos Sinos, Brasil Antonio Carlos Hohlfeldt, Pontifícia Universidade Católica do Rio Grande do Sul, Brasil Antonio Roberto Chiachiri Filho, Faculdade Cásper Líbero, Brasil Arlindo Ribeiro Machado, Universidade de São Paulo, Brasil Arthur Autran Franco de Sá Neto, Universidade Federal de São Carlos, Brasil Benjamim Picado, Universidade Federal Fluminense, Brasil César Geraldo Guimarães, Universidade Federal de Minas Gerais, Brasil Cristiane Freitas Gutfreind, Pontifícia Universidade Católica do Rio Grande do Sul, Brasil Denilson Lopes, Universidade Federal do Rio de Janeiro, Brasi Denize Correa Araujo, Universidade Tuiuti do Paraná, Brasi Edilson Cazeloto, Universidade Paulista , Brasil

Eduardo Peñuela Cañizal, Universidade Paulista, Brasil

Eduardo Vicente, Universidade de São Paulo, Brasi

Eneus Trindade, Universidade de São Paulo, Brasi

Erick Felinto de Oliveira, Universidade do Estado do Rio de Janeiro, Brasi

Florence Dravet, Universidade Católica de Brasília, Brasi

Francisco Eduardo Menezes Martins, Universidade Tuiuti do Paraná, Brasil

Gelson Santana, Universidade Anhembi/Morumbi, Brasi

Gilson Vieira Monteiro, Universidade Federal do Amazonas, Brasil

Gislene da Silva, Universidade Federal de Santa Catarina, Brasil

Guillermo Orozco Gómez, Universidad de Guadalajara

Gustavo Daudt Fischer, Universidade do Vale do Rio dos Sinos, Brasil Hector 0spina, Universidad de Manizales, Colômbia

Herom Vargas, Universidade Municipal de São Caetano do Sul, Brasi leda Tucherman, Universidade Federal do Rio de Janeiro, Brasil

Inês Vitorino, Universidade Federal do Ceará, Brasil

Janice Caiafa, Universidade Federal do Rio de Janeiro, Brasil

Jay David Bolter, Georgia Institute of Technology

Jeder Silveira Janotti Junior, Universidade Federal de Pernambuco, Brasi João Freire Filho, Universidade Federal do Rio de Janeiro, Brasil
John DH Downing, University of Texas at Austin, Estados Unidos

José Afonso da Silva Junior, Universidade Federal de Pernambuco, Brasi José Carlos Rodrigues, Pontifícia Universidade Católica do Rio de Janeiro, Brasil José Luiz Aidar Prado, Pontifícia Universidade Católica de São Paulo, Brasil José Luiz Warren Jardim Gomes Braga, Universidade do Vale do Rio dos Sinos, Brasil Juremir Machado da Silva, Pontifícia Universidade Católica do Rio Grande do Sul, Brasil Laan Mendes Barros, Universidade Metodista de São Paulo, Brasi Lance Strate, Fordham University, USA, Estados Unidos Lorraine Leu, University of Bristol, Grã-Bretanha Lucia Leão, Pontifícia Universidade Católica de São Paulo, Brasil Luciana Panke, Universidade Federal do Paraná, Brasil Luiz Claudio Martino, Universidade de Brasília, Brasi Malena Segura Contrera, Universidade Paulista, Brasil

Márcio de Vasconcellos Serelle, Pontifícia Universidade Católica de Minas Gerais, Brasil Maria Aparecida Baccega, Universidade de São Paulo e Escola Superior de Propaganda e Marketing, Brasi

Maria das Graças Pinto Coelho, Universidade Federal do Rio Grande do Norte, Brasil Maria Immacolata Vassallo de Lopes, Universidade de São Paulo, Brasil Maria Luiza Martins de Mendonça, Universidade Federal de Goiás, Brasil Mauro de Souza Ventura, Universidade Estadual Paulista, Brasil

Mauro Pereira Porto, Tulane University, Estados Unidos

Nilda Aparecida Jacks, Universidade Federal do Rio Grande do Sul, Brasi Paulo Roberto Gibaldi Vaz, Universidade Federal do Rio de Janeiro, Brasi Potiguara Mendes Silveira Jr, Universidade Federal de Juiz de Fora, Brasi Renato Cordeiro Gomes, Pontifícia Universidade Católica do Rio de Janeiro, Brasil Robert K Logan, University of Toronto, Canadá Ronaldo George Helal, Universidade do Estado do Rio de Janeiro, Brasil Rosana de Lima Soares, Universidade de São Paulo, Brasi Rose Melo Rocha, Escola Superior de Propaganda e Marketing, Brasil Rossana Reguillo, Instituto de Estudos Superiores do Ocidente, Mexico Rousiley Celi Moreira Maia, Universidade Federal de Minas Gerais, Brasi Sebastião Carlos de Morais Squirra, Universidade Metodista de São Paulo, Brasil Sebastião Guilherme Albano da Costa, Universidade Federal do Rio Grande do Norte, Brasil

Simone Maria Andrade Pereira de Sá, Universidade Federal Fluminense, Brasi Tiago Quiroga Fausto Neto, Universidade de Brasília, Brasil Suzete Venturelli, Universidade de Brasília, Brasil Valerio Fuenzalida Fernández, Puc-Chile, Chile

Veneza Mayora Ronsini, Universidade Federal de Santa Maria, Brasi Vera Regina Veiga França, Universidade Federal de Minas Gerais, Brasil

COMISSÃO EDITORIAL

Adriana Braga I Pontifícia Universidade Católica do Rio de Janeiro, Brasil

CONSULTORES AD HOC

Adriana Amaral, Universidade do Vale do Rio dos Sinos, Brasil

Alexandre Rocha da Silva, Universidade Federal do Rio Grande do Sul, Brasi

Arthur Ituassu, Pontifícia Universidade Católica do Rio de Janeiro, Brasil

Bruno Souza Leal, Universidade Federal de Minas Gerais, Brasil

Elizabeth Bastos Duarte, Universidade Federal de Santa Maria, Brasil

Francisco Paulo Jamil Marques, Universidade Federal do Ceará, Brasi

Maurício Lissovsky, Universidade Federal do Rio de Janeiro, Brasi

Suzana Kilpp, Universidade do Vale do Rio dos Sinos, Brasil

Vander Casaqui, Escola Superior de Propaganda e Marketing, Brasil

EDIÇÃO DE TEXTO E RESUMOS I Susane Barros

SECRETÁRIA EXECUTIVA I Juliana Depiné

EDITORAÇÃO ELETRÔNICA I Roka Estúdio

TRADUÇÃ̃o I Sieni Campos
COMPÓS I www.compos.org.br

Associação Nacional dos Programas de Pós-Graduação em Comunicação

Presidente

Eduardo Morettin

Universidade de São Paulo, Brasil

eduardomorettin@usp.br

Vice-presidente

Inês Vitorino

ines@ufc.br

Secretária-Geral

Gislene da Silva

Universidade Federal de Santa Catarina, Brasi

gislenedasilva@gmail.com
Universidade Federal do Ceará, Brasil 